\title{
DEVELOPMENT OF NEW TECHNOLOGIES TO ENABLE THE CREATION OF VIRTUAL ENTERPRISES IN THE LEATHER SECTOR
}

\author{
Myrna Flores and Marzio Albertoni \\ University of Applied Sciences of Southern Switzerland (SUPSI), \\ CIM Institute of Southern Switzerland-iCIMSI \\ myrna.flores@icimsi.ch,marzio.albertoni@icimsi.ch
}

SWITZERLAND

\begin{abstract}
The concept of Virtual Enterprise proposes a way of collaboration for different companies to exploit business opportunities to fulfil continuously changing market needs. This paper presents the approach proposed in Mastrit Skin project for the development of new technologies for the leather sector that will enable the formation of new virtual enterprises. The main objectives of this research are: (i) analyse the "as is" state of the leather sector, (ii) perform an initial insight of the leather industry Clusters and the need of a Broker to promote, initiate and create new Virtual Enterprises and (iii) describe how the proposed new technologies will be developed by the the formation of Virtual Enterprises.
\end{abstract}

\section{INTRODUCTION}

Mastrit Skin 2002 E!2223 is an Eureka project performed in collaboration with both Swiss and Italian universities and six main industrial partners. The first phase of the Swiss project, called Mastrit Skin 2002 Quality Standard and Global Concept, has the objective to analyze the supply chain and design a B2B architecture to improve leather selection and procurement. The main deliverable will be a global concept to understand the state of the art in the leather sector and identify the technological and organizational needs and feasibility to implement new solutions. The overall project intends to develop a unified leather quality standard with measurable parameters, digital maps to obtain leather characteristics in a digital way, and a B2B platform to provide information to all business entities in the supply chain to improve their collaboration and be able to sell and buy leather in a global way (Flores, et. al, 2002). The Italian project has as main objective to design and develop a system to capture and catalogue in an automatic way defects on worked skins to optimize the inner process at the tannery.

The business model to be developed and implemented in the project for the development of the new proposed technologies is based on the concept of the Virtual Organization, where different independent companies, with different working philosophies, procedures, processes and products, collaborate in order to 
achieve a common goal and to compete in this global and changing economy (Flores et. al 2000). This type of organization can be seen as an instrument to improve SME's competitiveness, with the objective of improving their ability to respond to market requirements and changes, supplying altogether a final product (leather) based on the cooperation, experience and know how of every single partner. As a consequence the adoption of new ways of relationships and partnerships among customers and suppliers needs to be constructed (Horton et al 2002). The supply chain and virtual organization analysis research is being carried out within workpackage 3.2, where four different partners from the National Network of Excellence of the Universities of Applied Sciences in Integrated Production and Logistics, Switzerland (IPLnet, 2003) collaborate to achieve the project objectives.

\section{THE LEATHER SECTOR}

The leather industry utilizes a by-product of slaughterhouses and transforms the raw materials into various types of leather and manufactured end products. The leather production-consumption chain has three processing stages, each requiring different combinations of material inputs, labour and capital. The first stage is the recovery of raw materials, which has direct links with animal production activities; hides and skins are recovered from dairy, draught animals or animals from slaughter houses. Leather tanning and finishing is the second stage that involves several capital-intensive operations while the third stage, which is the production of leather products, is a more labour intensive activity. These three processing stages are linked to key commercial components of the chain, the marketing of intermediate inputs, components and end products, and trade and consumption. Inputs to the sector without which the chain cannot operate under competitive basis are: qualified labour, design and art canters, component production, access to chemicals, technical and administrative support institutions, research and development, training as well as a set of adequate policies (Factbook, 2003).

In the last decade, European finished leather exports to other regions in the world have experienced an extraordinary development. Manufacturers in new and emerging markets are particularly keen to develop trade relations with European tanners and to work closely with them. Small and medium sized companies predominate in the European tanning sector. The consequent flexibility, adaptability and the quick response to demand constitute some of the industry's most important assets. Larger companies, however, excel thanks to their capacity to be at the forefront of technological developments and to constitute reliable partners in global business activities. Technological leadership, fashion, design, quality, excellent raw materials and the sense of service to the customer are all factors contributing to the strength of European tanners. Continuing modernisation combined with investment in training, environmental infrastructure, R\&D and export promotion allow the industry's operators to look to the future with confidence. Table 1 shows leather production statistics of European countries (COTANCE 2000). 
Table 1.Leather Production in European Countries (COTANCE 2000)

\begin{tabular}{|r|r|r|r|r|r|r|}
\hline \multicolumn{1}{|c|}{$\mathbf{2 0 0 0}$} & $\begin{array}{c}\text { Employme } \\
\text { nt }\end{array}$ & Companies & \multicolumn{2}{|c|}{ Turnover } & \multicolumn{1}{c|}{ Export } & \multicolumn{2}{c|}{ Production $\left(\mathbf{0 0 0} \mathbf{~ m}^{2}\right)$} \\
\hline & & & \multicolumn{2}{|c|}{$(1000$ EURO } & \multicolumn{1}{c|}{ cattle/calf } & sheep/goat \\
\hline Italy & 30300 & 2400 & 6300800 & $59 \%$ & 168300 & 46550 \\
\hline Spain & 7399 & 223 & 1288570 & $39 \%$ & 28300 & 20850 \\
\hline UK & 3400 & 43 & 580000 & $63 \%$ & 11500 & 3200 \\
\hline Germany & 3211 & 27 & 546000 & $48 \%$ & 16000 & incl.cattle \\
\hline France & 2583 & 84 & 325000 & $42 \%$ & 6000 & 4150 \\
\hline Portugal & 1835 & 26 & 253219 & $18.8 \%$ & 9593 & 1288 \\
\hline Sweden & 430 & 4 & 68500 & $85 \%$ & 2600 & \\
\hline Ireland & 400 & 2 & 40000 & $100 \%$ & 4080 & 67 \\
\hline Belgium & 169 & 4 & 35667 & $73 \%$ & 349 & 836 \\
\hline Finland & 229 & 16 & 28214 & $42 \%$ & 626 & 127 \\
\hline Denmark & 150 & 1 & 20000 & $85 \%$ & 725 & \\
\hline EU-15 & 52506 & 2856 & 9485970 & $59.5 \%$ & 248087 & 77068 \\
\hline
\end{tabular}

\subsection{The Supply Chain AS IS Analysis of Mastrit Skin Partners}

Supply chain management is a collaborative-based strategy to link cross-enterprise business operations to achieve a shared vision of market opportunity, where there is an upstream of information from the point of sales to raw material suppliers and a downstream of goods from supplier to retailers and to final consumers (Tellarini, et. al 2002). The supply chain could be optimized by the integration of four core processes among its different entities (SCOR, 2003): 1) Plan 2) Source 3) Make and 4) Deliver. This reference model was used to analyze the current business processes, the relationships among tanneries and final producers and impact of the proposed technologies on the leather value chain.

For the development and implementation of the Virtual Enterprise concept in the leather sector, a detailed analysis of the current supply chain is required. Main processes should be identified and information and physical flows between the different business entities need to be understood. Another key activity is to identify how processes will change within the supply chain after the TO BE implementation, and the impact on the physical, legal and social/cultural infrastructures when creating a Virtual Enterprise.

For State of the Art analysis in the Mastrit Skin project two entities in the chain were considered: the tanneries and the final producers. Leather distributors were also identified as an entity of the chain; nevertheless the main focus of the Mastrit Skin in this first stage of the research was the current types of coordination among tanneries and final producers (shoes, furniture and bags). The main findings are:

1. The alignment of business processes using Internet (E-business) is so far not a business practice. Many leather portals were found, where news, events, companies' directories and leather offers are published. Nevertheless a B2B marketplace in the leather sector, allowing full integration of processes, was not 
identified. It was also observed that the bigger companies in the Mastrit Skin project use ERP systems, such as SAP, for some processes such as finance information; nevertheless the smaller ones don't have an ERP. Internet is mainly used for image or to be present in the World Wide Web. No buying or selling transactions are carried out over the Internet; most business transactions are done using the telephone or fax. Generally speaking, this is the state of the art of the entire sector, as analyzed by an Italian company named Marknetting s.r.l. The results of the study done in mid 2001 in the tannery sector with 51 companies over the world reveal that the "Internet is being under-utilised. Most companies use the Internet mainly as a means of communication and for the company's image; not for developing commercial, marketing, and customer service solutions" Golfieri (2001). On the other hand, one of the project partners started in March 2003 to offer leather with a catalogue on their website.

2. Regarding the procurement process, for SME's the leather selection process is simple. As most of the times, small quantities are acquired, tanneries are contacted via phone, fax or e-mail asking to purchase the required leather. They work usually under a customized type of production focused more on local markets. Their relationships are close so as a consequence the quality requirements are known by experience. For bigger well known fashion companies, quality specifications are very strict as their product brands are recognized in international markets. Thus, the purchasing process is much more complex, costly and time consuming (Flores, et al 2003).

3. Information management in tanneries and final producers is done independently, where each element keeps most of its processes information internally such as business objectives, demand analysis, inventory levels, orders, production capacity. This fact impacts on a high degree the overall supply chain performance: due to the lack of information, it is difficult to optimize the operative activities in the chain such as production, transportation, warehousing, etc, from tanneries and final producers. Thus, there is a big opportunity to evolve to a networked sector, where the transparency of information and alignment of business processes, specially procurement and capacity allocation allow a better planning of every element and thus the increase of the overall chain performance.

4. Another critical point is the low understanding/knowledge from companies of how to apply supply chain and virtual enterprise concepts for improvement. An effort will be made in the next phase of the project to train the participating companies in these topics so industrial partners can identify the benefit to evolve into a collaborative network which shares practices and methods.

5. Participating companies measure in a low degree their performance with well defined indicators. The usage of scorecards improves the knowledge of the current processes and is the base for identifying continuous improvement projects and how the new proposed technologies will impact their business. The development of scorecards is also an opportunity area the main tasks for the next phase of the project.

6. Finally, the pricing of leather is a very sensitive point for partners. Tanneries don't have yet enough trust to provide costs and prices structures for the B2B creation. A new model for costing and pricing of leather is required to offer the services in the B2B. 


\section{ENABLING THE FORMATION OF VIRTUAL ENTERPRISES IN THE LEATHER SECTOR}

Virtual enterprises can be seen as an enabler for SME's to handle complex tasks that could probably not be accomplished independently. A Virtual Organisation can perform tasks that could not be done by each of the competitors working sequentially or even in tandem, because is formed by integrating core competencies, resources and opportunities (Goldman, Nagel and Preiss, 1995). Before any VE incubation, two main elements should be analyzed and taken into consideration: 1) Virtual Industry Clusters and 2) a Broker. These two elements are required to configure and manage partners' capabilities or core competencies to accomplish a specific objective or business opportunity.

\subsection{Identifying Leather clusters in Italy}

After analysing Table 1, it was observed that $84 \%$ of the leather producers in Europe are located in Italy with a total turnover ratio in Europe of $66 \%$ and a calf leather final production ratio of $68 \%$. This motivates the research of leather clusters in Italy to identify how they work, which technologies they use, which are their markets, needs and opportunity areas.

In Italy, two main clusters of tanneries were identified: the first one located in Chiampo Valley and the second one in Tuscany. Leather manufacturing is traditionally rooted in the Chiampo Valley. The earliest evidence of such an industry dates back to the 15th Century. The oldest among the enterprises which are still active in Arzignano was founded in 1830. It was only in the post war period, that leather manufacturing gained the central role in the local economy. In 1956 only 27 enterprises operated in Arzignano, but by 1961 this number had already grown to 70 . In the late 1980 s more 600 enterprises were localized within the district while more than 750 are currently active (Russo, 2003). The area is also called the "leather triangle", which is located in the Chiampo Valley near Vicenza (north-east Italy) around the towns of San Pietro, Chiampo, Arzignano, Trissino, Montorso, Zermeghedo and Montebello. In an area inhabited by nearly 90,000 people, leather manufacturing is done by approximately 8,500 workers. The district is composed of some 750 enterprises, over a third of which are handcraft workshops. The district also houses a great deal of metalworking and chemical enterprises that supply the machinery and the chemicals which are required in leather production. Recently, the machinery producers have established themselves as exporters within the European market, competing against the traditionally leading German and French producers. In 1996, the leather triangle manufactured some 900 square meters of leather. Nearly one third of the leather manufactured within the district is exported (Germany, USA and the Far East being the key markets). Arzignano accounts for nearly $40 \%$ of the Italian leather production. The leather triangle cluster focuses on three main markets: 1) the furniture industry, 2) increasingly the car industry and 3) clothing industry (shoes, bags, leather jackets). These first two markets are currently addressed only by the older tanneries of the area which have established a well-recognized brand and which have also invested on the manufacturing of high quality leather. The third 
market segment is supplied by small-sized companies that produce small batches of goods with high fashion content and a relatively short product life.

Other major Italian leather producers are located in Tuscany (Santa Croce) and Avellino (Solofra) but they operate on a smaller scale and on different market segments. The major competitors are located in the Far East, in India and in Eastern Europe (where labour costs are lower and where environmental protection legislation is less stringent). The district enjoys a market leadership on its traditional core business (production for the furniture industry). For the Mastrit Skin project, these two clusters (Chiampo Valley and Tuscany) could be approached for the implementation of the new technologies. At the moment, one of the main tanneries located in Arzignano is one of the main project partners.

\subsection{Collaboration in clusters, how can it start?}

There is mounting evidence that clustering and networking help small firms to compete and grow. By working together, firms can gain the benefits of collective efficiency, enabling them to challenge larger competitors and break into national and global markets. Comparing experience in different countries, there are three factors which seem critical to the success of schemes aimed at encouraging the growth of small firms. To be effective, interventions need to be: customeroriented, collective and cumulative (Anderson et.al 1997).

One observation done in the analysis of the leather sector is that the broker element as a coordinator of partners' competences and searcher of market opportunities does not exist. This means that no aggregation of competencies (in terms of products, processes or technologies) managed by one entity towards one common objective was identified. Each company accomplishes specific orders to specific customers. For the creation of a Virtual Enterprise in the leather sector the broker element is required, to manage and coordinate partners' capabilities. As mentioned before, for example in the Chiampo Valley cluster, the furniture and automotive sectors work so far only with bigger tanneries. This for instance, could be an opportunity for smaller firms to aggregate their production to have "one face" or name for a customer that will probably ask for high volumes. Another option is that the bigger tanneries start to recognize a SME cluster as a high quality network supplier where production could be outsourced when there is a very high volume order that can not be supplied with its current capacity. These are only initial ideas of how the leather cluster could collaborate to be more competitive. For this, further research is required such as the development of specific scenarios and collaboration models that can attract SME's to form well organizing clusters that enable a new breeding environment to increase market opportunities.

\section{THE CREATION OF TWO VIRTUAL ENTERPRISES FOR THE MASTRIT SKIN PROJECT}

The Mastrit Skin project intends to develop two main new technologies: 1) a device to capture and catalogue in an automatic way defects on worked skins providing leather digital maps with measurable quality parameters and 2) a B2B 
platform capable of providing new services such as the e-procurement and the nesting of leather. To be able to achieve this, several competencies and areas of knowledge are required from both academic and industrial partners. By definition, the purpose of the virtual enterprise is to create a temporary network of partners to aggregate different competencies to develop in the most efficient way new solutions. To accomplish the project objectives, two main virtual enterprises are foreseen to develop both technologies. Fugurel shows how the different proposed clusters and brokers interact, to develop two new virtual enterprises.

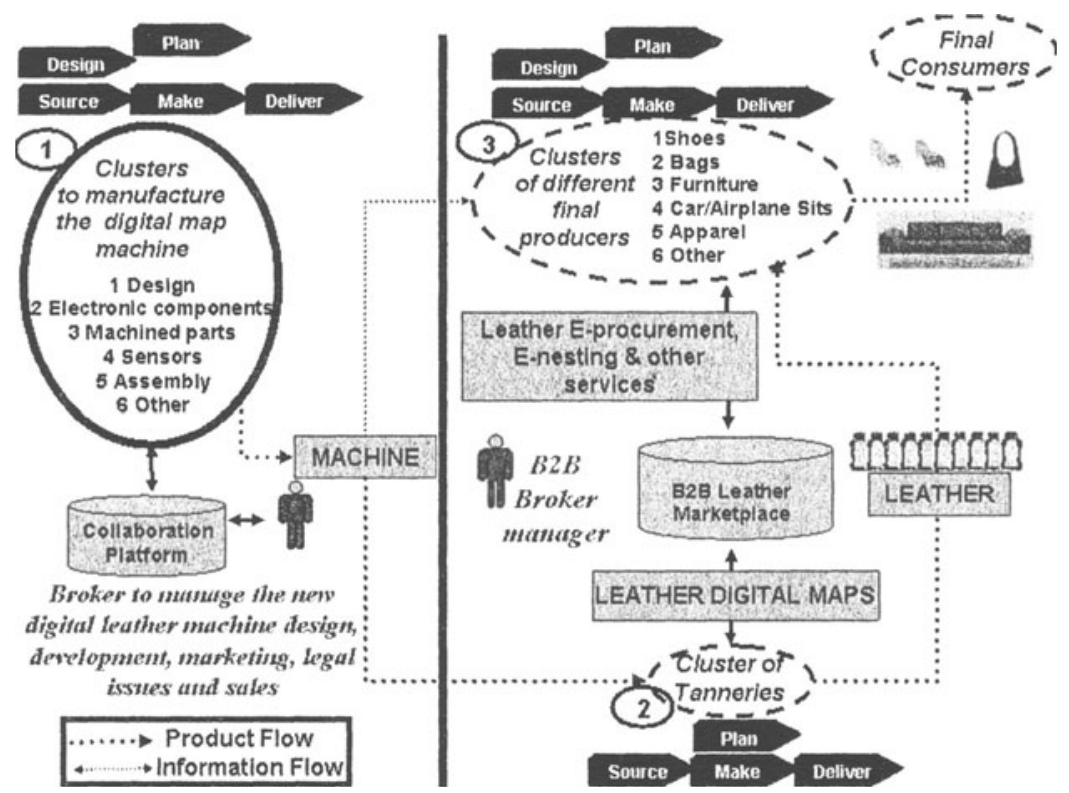

Figure 1. Virtual Clusters and Broker Interaction for the creation of Virtual Enterprises in the leather sector.

The initial and current state is the creation of three main clusters: 1) partners for the design, development and manufacturing of the machine that will deliver leather digital maps with measurable quality parameters, 2) companies in the tannery sector to sell leather using a B2B platform and 3) final producers who sell to final consumers and provide feedback from the market trends. Another cluster could be developed for the cutting of leather as this activity has been identified not as a core competence so it could be outsourced by the final producers. In parallel, one or two different brokers are required 1) one that can manage and maintain the B2B infrastructure and could represent a SME tannery cluster to identify global opportunities and 2) one that can manage the partners that will develop the device to obtain the digital maps. As observed in the figure, the machine could be sold both to tanneries of final producers, nevertheless the focus in the project so far is to sell it to tanneries. There is also a possibility that one broker could perform both tasks. A Swiss industrial partner participating in the Mastrit Skin project is already interested to be the broker for the machine development and B2B leather marketplace services. It is still not decided if one or two brokers will be required for all the development and operation of the proposed 
technologies. Once the solutions are deployed and implemented the dissolution of the Virtual Enterprise will take place, then a stable supply chain or extended enterprise of partners will last to take advantage of the complete product life cycle of both technologies.

\section{CONCLUSIONS}

This paper proposes the creation of two virtual enterprises for the design and development of a new technologies to improve the competitiveness of SME's in the leather sector. The Mastrit Skin project proposes the formation of a collaborative environment including different industrial clusters and brokers which will allow future incubation of other Virtual Enterprises. The creation of this type of networks will allow the delivery of higher value products (leather digital maps with quality parameters) and services (e-procurement and nesting). The proposed new Virtual Enterprises also require processes modelling, business scenarios formation and methods to support the legal, physical, ICT and cultural/social infrastructures which will be carried out in the next phase of the project.

\section{REFERENCES}

Anderson E and Schmitz H. Collective Efficiency: A way forward for small firms, IDS Policy Briefing, Institute of Development Studies, at the University of Sussex Issue 10 April 1997, http://www.ids.ac.uk/ids/bookshop/briefs/brief10.html

COTANCE - Confederation of National Associations of Tanners and Dressers of the European Community http://www.euroleather.com/statisti.htm (2000)

Flores M and Molina A, "Methodology for the Creation of Virtual Industry Clusters", Information Technology for Balanced Automation Systems in Production and Transportation, BASYS October 2000.

Flores M, Longhi R, Albertoni M, Ferroni B, Mastrit Skin 2002 Quality Standard \& Global Concept, IPLnet Conference, Saas Fee 2002.

Flores M, Albertoni M, Bourban Y, Siegenthaler M., E-business and Supply Chain Integration for the Leather Industry, IMS 2003 7th IFAC Workshop on Intelligent Manufacturing Systems, 2003

Factbook 2003, The Leather Global Value Chain and the World Leather footwear market http://www.factbook.net/, March 2003.

Goldman, Nagel and Preiss, 1995, Agile Competitors and Virtual Organizations, Strategies for enriching the customer, Van Nostrand Reinhold Book

Golfieri (2001), S, Internet and the tannery sector, http://www.tanneryandmore.com/news/conciainterneten.asp. Site found: February 2003.

Horton A, Pawar K, "Understanding the nature of working relationships and interactions in virtual enterprises", collaborative business ecosystems and virtual enterprises, editor: Luis $M$. Camarinha-Mateos, IFIP - Kluwer academic publishers, April 2002

IPLnet, Swiss Integrated Production and Logistics Network, www.iplnet.ch, 2003

Russo F., The UNIDO Cluster/Network Development Programme: Arzignano Cluster Profile, http://www.unido.org/en/doc/4301, January 2003.

Supply Chain Council Reference Model, http://www.supply-chain.org, March 2003

Tellarini F. Pellandini S. Battezzati L. Fascina G. Ferrozzi C. "Designing the Supply Chain" in The Essentials of Logistics Management, editors Perret F.and Jaffreux C., 2002). 